\title{
Reduced expression of folate transporters in kidney of a rat model of folate oversupplementation
}

\author{
Shilpa Thakur · Som Dev Thakur • \\ Nissar Ahmad Wani $\cdot$ Jyotdeep Kaur
}

Received: 17 July 2013/ Accepted: 12 November 2013/Published online: 4 December 2013

(C) Springer-Verlag Berlin Heidelberg 2013

\begin{abstract}
Folic acid is the key one-carbon donor required for de novo nucleotide and methionine synthesis. Its deficiency is associated with megaloblastic anemia, cancer and various complications of pregnancy. However, its supplementation results in reduction of neural tube defects and prevention of several types of cancer. The intake of folic acid from fortified food together with the use of nutritional supplements creates a state of folate oversupplementation. Fortification of foods is occurring worldwide with little knowledge of the potential safety and physiologic consequences of intake of such high doses of folic acid. So, we planned to examine the effects of acute and chronic folate oversupplementation on the physiology of renal folate transport in rats. Male Wistar rats were procured and divided into two groups. Rats in group I were given semisynthetic diets containing $2 \mathrm{mg}$ folic acid/ $\mathrm{kg}$ diet (control) and those in group II were given folate-oversupplemented rat diet, i.e., $20 \mathrm{mg}$ folic acid/kg diet (oversupplemented). Six animals from group I and group II received the treatment for 10 days (acute treatment) and remaining six for 60 days (chronic treatment). In acute folate-oversupplemented rats, $5-\left[{ }^{14} \mathrm{C}\right]$-methyltetrahydrofolate uptake was found to be significantly reduced, as compared to chronic folate-oversupplemented and control rats. This reduction in uptake was associated with a significant decrease in the mRNA and protein levels of the folate transporters. Results of the present investigation showed that acute oversupplementation led to a specific and significant down-regulation of renal folate uptake
\end{abstract}

S. Thakur - S. D. Thakur · N. A. Wani · J. Kaur $(\bowtie)$

Department of Biochemistry, Postgraduate Institute of Medical

Education and Research, Chandigarh 160012, India

e-mail: jyotdeep2001@yahoo.co.in process mediated via transcriptional and translational regulatory mechanism(s).

Keywords Folate - Folate transport - FBP - PCFT RFC $\cdot$ Folate oversupplementation

\section{Introduction}

Folate is a water-soluble B vitamin present in serum either in free form or bound to carrier proteins and is filtered in the renal glomeruli. The requirement for folate is derived from the need to maintain tissue pools of tetrahydrofolates. These compounds act as substrates and coenzymes in the acquisition, transport, and enzymatic processing of onecarbon units for amino acid, nucleic acid metabolism, and metabolic regulation (Gregory and Quinlivan 2002). Kidneys play an important role in regulation of folate homeostasis via the uptake of folates across its membranes (Villanueva et al. 1998). Circulating folate is filtered in the glomeruli and extensively reabsorbed within the nephron to the renal vascular circulation. Urinary folate excretion is regulated by greater than $95 \%$ of tubular reabsorption at the kidney brush-border (KBB) membrane and is an important process in maintaining physiological folate homeostasis (Williams and Huang 1982). Estimations of the filtration fraction suggest that an efficient renal tubular reabsorption of folate is essential to prevent excessive urinary losses in both humans and animals.

Folate receptor $\alpha(\mathrm{FR} \alpha)$ expressed at the apical brushborder membrane and reduced-folate carrier (RFC) expressed at the basolateral membrane are positioned within the tubule to work in tandem in the process of folate reabsorption as the substrate moves from the apical to basolateral membrane and then into the peritubular fluid 
and capillaries (Wang et al. 2001; Birn et al. 2005). However, RFC's antiporter function favors transport into the cells. In addition to the above-mentioned transporters, proton-coupled folate transporter (PCFT) is highly expressed in the kidney (Qiu et al. 2006, 2007) while its location within the renal tubules has not as yet been clarified; the high level of low-pH folate transport activity in renal tubule brush-border membrane vesicles makes it likely that PCFT is expressed at this site (Bhandari et al. 1988, 1991).

In the Western Hemisphere, folate deficiency has been found to be the most prevalent vitamin deficiency and has been associated with megaloblastic anemia, increased risk of cardiovascular disease, cancer, growth retardation, and various complications of pregnancy (Martel et al. 2006). Folate supplementation provides a number of health benefits ranging from reduction of neural tube defects to the prevention of several types of cancer, cardiovascular disease, and possibly dementia. Because of these associated benefits, folate seems like a wonder drug, which is also safe for use as a chemopreventive agent. Although in recent years some warning lights have appeared regarding the excessive intakes of folic acid, which raised the need for investigations about the safe limit of the vitamin. The safety of chronic very high intakes of folic acid is largely unknown. The Institute of Medicine (US) recommends a tolerable upper intake level of $1,000 \mu \mathrm{g} / \mathrm{d}$ folic acid from supplements or fortified foods for adults and between 300 and $400 \mu \mathrm{g} / \mathrm{d}$ for children (Ulrich and Potter 2006). These upper intake levels were decided initially to avoid masking the anemia and missing the neuropathy of vitamin B12 deficiency because only little information was available on other possible adverse effects of chronic high intakes (Ulrich and Potter 2006). Taking into consideration the upper intake level, an adult who consumes two standard multivitamins daily ( $400 \mu \mathrm{g}$ each) can easily exceed the daily upper intake level, as can a child who consumes substantial amounts of breakfast cereals which are usually folic acid supplemented. The intake of folic acid from fortified food $(100-200 \mu \mathrm{g} / \mathrm{d})$ together with the use of nutritional supplements creates a state of folate oversupplementation in a significant segment of the population (Ulrich and Potter 2006). This practice is occurring with little knowledge of the potential safety and physiologic consequences of chronic intake of such high doses of folic acid. A few reports, however, have raised questions about the validity of such practices (Troen et al. 2006; Achon et al. 1999; Roncales et al. 2004). Folic acid was traditionally considered safe because of its water-soluble character (Butterworth and Tamura 1989). However, it is necessary to question whether extended supplementation with doses between 0.4 and $4 \mathrm{mg} / \mathrm{d}$ or food fortification is associated with adverse effects.
In countries such as USA and Canada, folic acid supplementation has reduced the incidence of neural tube birth defects by as much as $50 \%$, but at the same time, there has been another, totally unexpected development. All these countries have also seen rise in the rates of colorectal cancer and prostate cancer (Smith et al. 2008). Till date, only a few studies have been conducted to determine the harmful effects of folic acid oversupplementation. In our laboratory, we have studied the effect of acute and chronic folate oversupplementation on the folate transport process in rat intestine and observed that acute folate oversupplementation results in a significant decrease in intestinal folate uptake by down-regulating RFC and PCFT expression, via some posttranscriptional or translational mechanisms (Dev et al. 2011). Another study on long-term oversupplementation with folate in human cell lines showed specific and significant downregulation in intestinal and renal folate uptake, which was associated with decreased message levels of RFC, PCFT, and FR (Ashokkumar et al. 2007). Also, it was observed that dietary folate oversupplementation decreases the expression of reduced-folate carrier in an avian system (Jing et al. 2009). However, till date, only little information is available regarding the regulation of renal folate transport process during folate oversupplementation in a mammalian model. Therefore, we designed this study to examine the effect of acute and chronic folate oversupplementation on the physiology of renal folate transport in rats.

\section{Materials and methods}

\section{Chemicals}

Radiolabelled $5-\left[{ }^{14} \mathrm{C}\right]$-methyltetrahydrofolate and potassium salt with specific activity $24.0 \mathrm{Ci} / \mathrm{mmol}$ were purchased from Amersham Pharmacia Biotech (Hong Kong). Total RNA extraction kit was purchased from Taurus Scientific, Cincinnati, USA. Moloney murine leukemia virus reverse transcriptase (RevertAidTM M-MuLV RT) kit was purchased from the MBI Fermentas, Life Sciences, USA. RNAlater (RNA stabilization solution) was obtained from Ambion, Inc. Austin, USA. Primary antibodies such as rabbit, anti-rat RFC (rRFC), and anti-rat PCFT (rPCFT) polyclonal antibodies were raised in rabbits in our laboratory (Dev et al. 2011). HRP-labeled goat anti-rabbit-IgG secondary antibody was purchased from $\mathrm{G}$ Biosciences, $\mathrm{St}$ Louis, MO, USA. Metal-enhanced DAB substrate kit was purchased from Thermo Fisher Scientific Inc, Rockford, USA. Cryoprotected Lactobacillus casei bacterial strain (MTCC 1423) was purchased from IMTECH, Chandigarh, India. 
Animals

The study was performed in the department of Biochemistry, Postgraduate Institute of Medical Education \& Research (PGIMER), Chandigarh, India. Weaning male Albino rats (Wistar strain) weighing 60-80 g were obtained from central animal house of the institute. These were housed in polypropylene cages in the departmental animal house under hygienic conditions at controlled temperature $\left(23 \pm 1{ }^{\circ} \mathrm{C}\right)$ and humidity (44-55\%) and had $12 \mathrm{~h}$ dark-light cycle throughout the study. Rats were randomized into two groups of twelve animals each. Rats in group I were given semisynthetic diets containing $2 \mathrm{mg}$ folic acid $/ \mathrm{kg}$ diet (control) and those in group II were given folate-oversupplemented rat diet, tenfold rat requirement, i.e., $20 \mathrm{mg}$ folic acid/kg diet (oversupplemented) (Dev et al. 2011). Six animals each from group I and group II received the treatment for 10 days (acute treatment) and remaining six for 60 days (chronic treatment). Animals in both the groups were pair fed and had free access to water. The body weights of the rats were recorded twice weekly. Animals from both groups were killed under anesthesia using sodium pentothal.

The protocol of the study was approved by "Institutional Animal Ethical Committee" (IAEC) and "Institutional Biosafety Committee" (IBC).

Glucose, cholesterol and triglyceride estimation

Analyses of glucose, cholesterol and triglyceride were performed on the Beckman coulter AU2700 autoanalyzer using kit-based glucose oxidase PAP (GOD-PAP) method for glucose, glycerol-3-phosphate PAP (GPO/PAP) for triglyceride and cholesterol oxidase PAP (CHOD-PAP) for cholesterol.

Estimation of folate by microbiological assay

The folate levels in kidney tissue were determined by micotiter plate assay using L. casei as described earlier (Wani et al. 2011). All the steps were carried out in aseptic conditions. For measuring intracellular folate, $10 \%$ kidney homogenate was made in phosphate buffer, $\mathrm{pH} 6.3$, containing $5 \mathrm{mg} / \mathrm{mL}$ ascorbate. The homogenate was incubated at $110{ }^{\circ} \mathrm{C}$ for $10 \mathrm{~min}$ followed by centrifugation at $300 \mathrm{rpm}$ for $10 \mathrm{~min}$. After centrifugation, the supernatant was divided into two parts. One part of the supernatant $(0.1 \mathrm{~mL})$ was then treated with $0.02 \mathrm{~mL}$ of rat plasma conjugase in $0.375 \mathrm{~mL}$ of phosphate buffer of $\mathrm{pH} 4.5$ for $4 \mathrm{~h}$ for total folate determination. Rat plasma conjugase hydrolyzes polyglutamated form of folate to monoglutamated form and thus helps in determination of total folate levels. Another part of the supernatant was used as such to determine monoglutamated folate levels. Folate levels in the samples were corrected for the levels measured in $0.02 \mathrm{~mL}$ of rat plasma. The free folate, i.e., monoglutamated folate, was determined by a standard microbiological microtitre plate assay using L. casei. The polyglutamated folate form in the kidney was determined by subtracting total folate in free form (conjugase treated) with the folate levels obtained without conjugase treatment.

Isolation of membrane vesicles from renal tissue

Rat renal cortical brush-border membrane vesicles (BBMVs) were prepared by differential centrifugation as described earlier (Hamid and Kaur 2006). Basolateral membrane vesicles (BLMVs) from renal cortices were prepared by the self-generating percoll gradient method of Scalera et al. (1980) with some modifications (Hamid et al. 2009). The final pellet obtained was suspended in loading buffer (280 mM mannitol, 20 mM HEPES-Tris, pH 7.4) so as to obtain a protein concentration of approximately 5 $\mathrm{mg} / \mathrm{mL}$. These BBMV and BLMV were used to determine $5-\left[{ }^{14} \mathrm{C}\right]$-methyltetrahydrofolate uptake.

Transport of 5-[ $\left[{ }^{14} \mathrm{C}\right]$-methyltetrahydrofolate

Uptake studies were performed at $37{ }^{\circ} \mathrm{C}$ in the incubation buffer of $100 \mathrm{mM} \mathrm{NaCl}, 80 \mathrm{mM}$ mannitol, $10 \mathrm{mM}$ HEPES, $10 \mathrm{mM}$ 2-morpholinoethanesulfonic acid (MES), pHs 5.5 and 6 (BBMV and BLMV, respectively), and $0.5 \mu \mathrm{M}$ of $5-\left[{ }^{14} \mathrm{C}\right]$-methyltetrahydrofolate, unless mentioned. Ten microliters of renal brush-border and basolateral membrane vesicles (50 mg protein) from the control and oversupplemented rats were added to incubation buffer containing 5-[ $\left[{ }^{14} \mathrm{C}\right]-$ methyltetrahydrofolate of known concentration for different specific assays. Reaction was stopped by adding ice-cold stop solution containing $280 \mathrm{mM}$ mannitol, $20 \mathrm{mM}$ HEPES-Tris, $\mathrm{pH}$ 7.4, followed by rapid vacuum filtration. Non-specific binding to the filters was determined by residual filter counts after filtration of the incubation buffer and labeled substrate without vesicles, as described earlier (Hamid and Kaur 2006). The radioactivity retained by the filters was determined by liquid scintillation counting (Beckman Coulter LS 6500). For the determination of kinetic constants $K_{\mathrm{m}}$ and $V_{\max }$, transport of $5-\left[{ }^{14} \mathrm{C}\right]$-methyltetrahydrofolate (referred to as folate subsequently) was measured by varying the concentration of $5-\left[{ }^{14 \mathrm{C}}\right]$-methyltetrahydrofolate from 0.125 to $4.0 \mu \mathrm{M}$ in the incubation buffer of $\mathrm{pH} 5.5$ and 8 .

Real-time reverse transcriptase (RT)-PCR analysis

Total RNA was isolated from the kidney by using total RNA extraction kit, and cDNA synthesis was carried out 
from the purified and intact total RNA according to the manufacturer's instructions. Expression of $\mathrm{r} R F C, \mathrm{r} P C F T$, $r F B P$, and $\mathrm{r} G A P D H$ was evaluated using sequence specific primers corresponding to the sequence in the open-reading frame. Real-time PCR was carried out using a LightCycler (Roche LightCycler 480). Ten-microliter reactions were set up using $0.25 \mu \mathrm{M}$ of each primer and $5 \mu \mathrm{l}$ of SYBR Green master mix (LightCycler FastStart DNA MasterPlus SYBR Green I, Roche). Cycling conditions were as follows: denaturation $\left(95{ }^{\circ} \mathrm{C}\right.$ for $3 \mathrm{~min}$ ), amplification, and quantification $\left(94{ }^{\circ} \mathrm{C}\right.$ for $30 \mathrm{~s}$, annealing temperature (AT) for $30 \mathrm{~s}$ and $72{ }^{\circ} \mathrm{C}$ for $30 \mathrm{~s}$, with a single fluorescence measurement at the end at $72{ }^{\circ} \mathrm{C}$ for $30 \mathrm{~s}$ segment), which were repeated 40 times. Annealing temperatures (AT) and sequence primers are indicated below. Data were analyzed using LightCycler 480, version 1.5 analysis software (Roche). All real-time PCR results were expressed as mean values from 2 to 3 separate experiments using the same cDNA preparation. For each experiment, a non-template reaction served as the negative control. Target gene expression was normalized to glyceraldehyde-3-phosphate dehydrogenase.

\begin{tabular}{lll}
\hline Direction & Primer sequence $\left(5^{\prime}-3^{\prime}\right)$ & $\begin{array}{l}\text { Annealing } \\
\text { temperature } \\
\left({ }^{\circ} \mathrm{C}\right)\end{array}$ \\
\hline$R F C$ & & \\
$\begin{array}{l}\text { Forward } \\
\text { Reverse } \\
P C F T\end{array}$ & CATGCTAAGCGAACTGGTGA & 64 \\
Forward & AAGCCAGTTATGGGCAACAC & 56 \\
$\begin{array}{l}\text { Reverse } \\
F B P\end{array}$ & GGATAGGCTGTGGTCAAGGA & \\
$\begin{array}{l}\text { Forward } \\
\text { Reverse }\end{array}$ & CAACACAAGCCAGGAAGACA & 58 \\
$G A P D H$ & CAAGTCGGGGAACACTCAT & \\
Forward & GGCATCGTGGAAGGGCTCATGAC & 60 \\
Reverse & ATGCCAGTGAGCTTCCCGTTCAGC & \\
\hline
\end{tabular}

Western blot analysis

For protein expression studies, BBMV $(100 \mu \mathrm{g})$ isolated from epithelial cell preparations were resolved on $10 \%$ SDS-PAGE and transferred to PVDF membrane for $20 \mathrm{~min}$ at $15 \mathrm{~V}$. Western blotting was performed using the procedure described by Towbin et al. (1992), using polyclonal primary antibodies as rabbit anti-rat RFC (1:500 dilutions) raised against specific region of rat RFC synthetic peptide corresponding to amino acids 494-512 (Said et al. 2000).
The polyclonal antibodies against rPCFT (1:500 dilutions) were raised against specific region of rat PCFT synthetic peptide corresponding to amino acids 442-459. The immunogenic property of this peptide corresponding to PCFT protein was determined by using the DNA STAR software (Madison, Wisconsin USA). The primary antibodies against FBP and $\beta$-actin (1:400 dilutions) were obtained from Santa Cruz Biotechnology, USA. HRPlabeled goat anti-rabbit-IgG secondary antibody (1:5,000 dilution) was used for this study. The quantification of blots was carried out by using 'Scion image'.

Statistical analysis

Each uptake assay was performed thrice with four to six independent preparations from each group. Data were computed as mean \pm SEM. Group means were compared by using the two-way anova (GraphPad Prism software) where fixed variables were time, $\mathrm{pH}$, structural analogs and folate oversupplementation dose. When variable interaction found to be statistically significant, post hoc test (Bonferroni test) was used to differentiate the treatments at the various times, $\mathrm{pH}$, and structural analogs. For comparison between two groups, Student's $t$ test was used. Differences were considered to be significant when $p<0.05$.

\section{Results}

There was no significant change in the body weight of the folate-oversupplemented rats compared with the controls, during the course of the experiment both in acute and chronic treatments. At the time of killing, the mean body weights of the control and folate-oversupplemented rats in the acute group were $103 \pm 2.4$ and $105 \pm 3.2 \mathrm{~g}$, whereas those in the chronic folate oversupplementation group were $236 \pm 6.5$ and $245 \pm 9.4 \mathrm{~g}$, respectively.

Serum glucose, triglyceride, and cholesterol levels

There were no significant changes in the levels of glucose, triglycerides, and cholesterol among control versus oversupplemented groups (data not shown).

Tissue folate levels

The total folate (i.e., monoglutamated and polyglutamated folate) levels were significantly increased in the kidney tissue. The extent of increase was $24 \%(p<0.05)$ and $32 \%(p<0.01)$ in the acute and chronic oversupplemented rats, respectively, as compared to their respective controls. Monoglutamated folate levels were more 


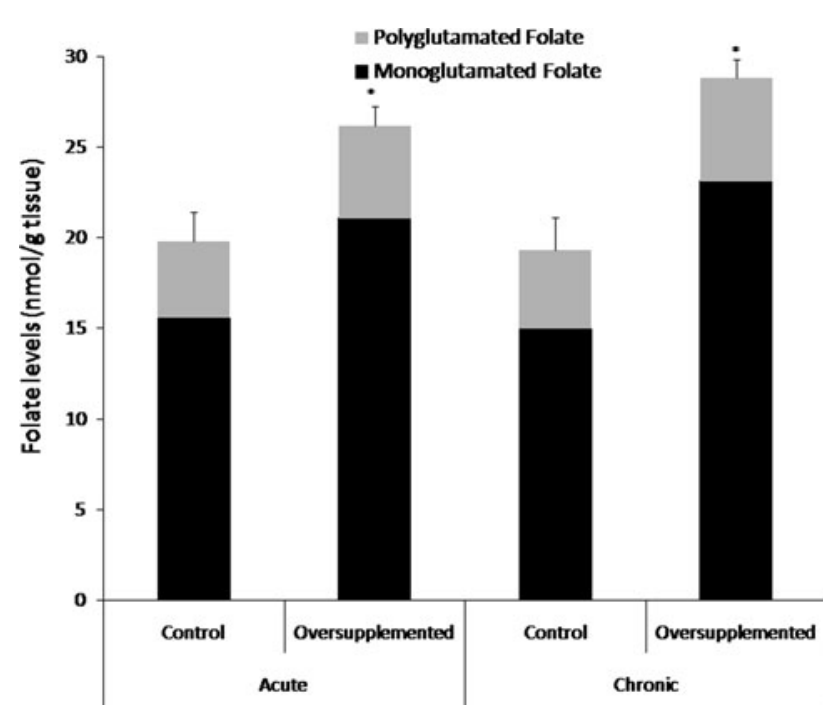

Fig. 1 Tissue folate levels of control, acute and chronic folateoversupplemented diet fed rats. Results are presented as mean \pm SD of three experiments. ${ }^{*} p<0.05$ versus control

increased as compared to polyglutamated folate levels on folate oversupplementation. In case of monoglutamated folate form, there was a 26 and $35 \%$ increase upon acute and chronic treatment, respectively, as compared to control; however, polyglutamated folate form was increased by 17 and $23 \%$ on acute and chronic folate oversupplementation, respectively $(p<0.01)$ (Fig. 1).

Folic acid transport across renal brush-border and basolateral membrane vesicles

Folic acid uptake was significantly decreased across the renal BBM $(40 \% ; p<0.01)$ and BLM $(24 \% ; p<0.01)$ in acute folate-oversupplemented group compared with the control group (Fig. 2). However, in the chronic folateoversupplemented group, there was no significant change in folate transport compared with the control group. Hence, the kinetic characterization of the folic acid transport across renal BBMV and BLMV was carried out in the acute folate-oversupplemented group only.

Kinetic characterization of folic acid uptake across renal brush-border membrane vesicles

BBMV from the control and folate-oversupplemented rats were incubated with $\left[{ }^{14} \mathrm{C}\right]-5$-methyltetrahydrofolate, and the transport was studied at various time intervals, i.e., 10, $20,30,60,120$, and $240 \mathrm{~s}$ at $37{ }^{\circ} \mathrm{C}$. Significant interaction was observed between time and folate oversupplementation dose as computed from two-way anova $(p<0.01)$. The initial substantial increase in uptake was observed within $20-30 \mathrm{~s}$ in both groups of rats. At different time intervals studied, the uptake was $26.5-47.6 \%$ less in the folate-oversupplemented rats (Fig. 3a). In order to determine the driving force for folate transport across the renal $\mathrm{BBM}$, the $\mathrm{pH}$ of the incubation buffer was varied from 4.5 to 8 , keeping the intravesicular $\mathrm{pH}$ constant at 7.4. As shown in Fig. 3b, maximum folate uptake was observed at pH 5.5 in both groups of rats with significant interaction between $\mathrm{pH}$ and oversupplementation dose $(p<0.05)$. Moreover, at the different $\mathrm{pH}$ points studied, the folic acid uptake was $16.6-41.4 \%$ less in the oversupplemented group. Furthermore, since the saturable kinetics is a notable characteristic feature of carrier-mediated transport, kinetic studies were performed in the presence of increasing concentrations of the substrate from 0.125 to $4.0 \mu \mathrm{M}$. The initial velocity determined at $30 \mathrm{~s}$ and at $\mathrm{pH} 5.5$ showed that, in both groups, the saturation phenomenon with a plateau at $1.0 \mu \mathrm{M}$ of the substrate concentration was indicative of the Michaelis-Menten kinetics (Fig. 4). At the physiological range of folic acid $(0-1.0 \mu \mathrm{M})$, the uptake was $15.2-40.7 \%$ less in the folate-oversupplemented group $(p<0.05)$. Further from the data, the kinetic constants $K_{\mathrm{m}}$ and $V_{\max }$ values were determined by the Lineweaver-Burk plot. $K_{\mathrm{m}}$ values for the control and folateoversupplemented groups were $0.324 \pm 0.034$ and $0.56 \pm 0.09 \mu \mathrm{M}$, respectively $(p<0.05)$. The values of $V_{\max }$ for the control and folate-oversupplemented rats were $64.24 \pm 2.42$ and $56.9 \pm 3.23 \mathrm{pmol} / 30 \mathrm{~s}$ per $\mathrm{mg}$ protein, respectively $(p<0.05)$. Furthermore, in order to determine the specificity of the transport system in the renal BBM, the folate transport was measured in the presence of the structural analogs, i.e., unlabeled folic acid, methotrexate, and inhibitors, i.e., thiamine pyrophosphate (inhibitor of RFC) and hemin (weak inhibitor of PCFT). The effect of structural analogs and inhibitors of RFC and PCFT on 5-methyltetrahydrofolate $(0.5 \mu \mathrm{M})$ uptake was determined (Fig. 5). No significant interaction was observed between structural analogs and oversupplementation dose. However, within each group there was significant effect of structural analogs and inhibitors on folate uptake, indicating the specificity of folate transport across renal BBMV. The structural analog methotrexate decreased the transport by $37.9 \%(p<0.001)$ and $34.6 \%(p>0.05$, non-significant) and unlabeled folic acid decreased the transport by $47.2 \%(p<0.001)$ and $35.9 \%(p<0.05)$ in the control and oversupplemented rats, respectively. The inhibitor hemin decreased the transport by $30.3 \%$ $(p<0.01)$ in the control and $26.8 \%(p<0.05$, significant) in oversupplemented rats. However, there was no significant decrease in the transport of folate in the presence of thiamine pyrophosphate in both the groups. Also, no significant difference was observed in the degree of inhibition of folate transport by these structural analogs and inhibitors in oversupplemented group as compared to control group. 


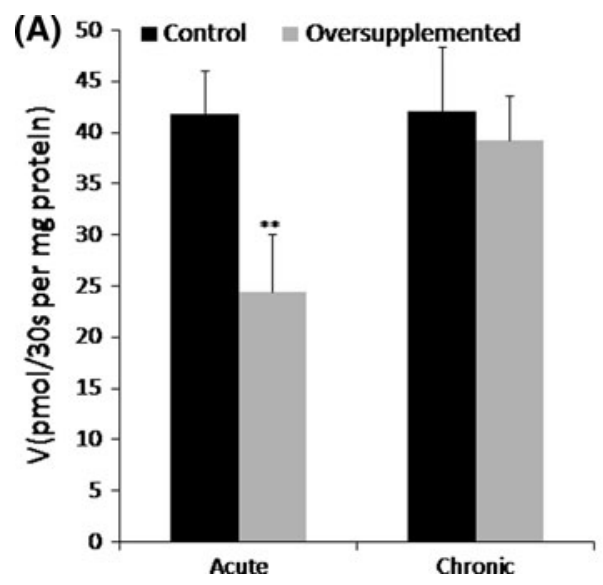

Fig. 2 Folate uptake in the renal brush-border and basolateral membrane vesicles after acute and chronic folate oversupplementation. Uptake of $\left[{ }^{14} \mathrm{C}\right]-5$-methyltetrahydrofolate $(0.5 \mu \mathrm{M})$ was measured $(\mathbf{a})$ in a buffer of $\mathrm{pH} 5.5$ across BBMV and $\mathbf{b}$ in a buffer of $\mathrm{pH} 6.0$ across

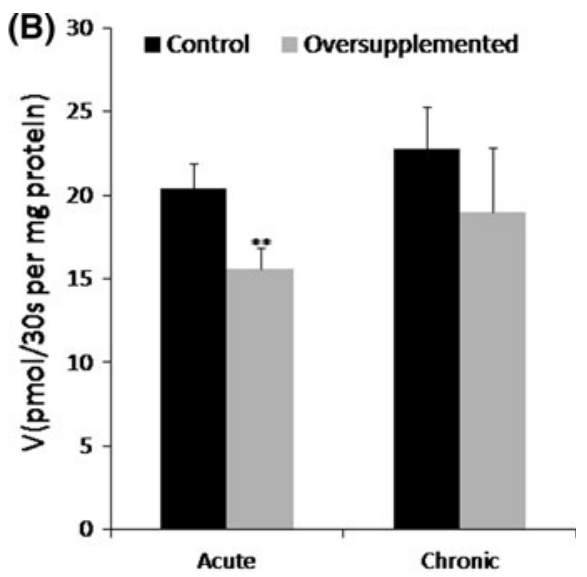

BLMV [100 mM NaCl, $80 \mathrm{mM}$ mannitol, $10 \mathrm{mM}$ HEPES, $10 \mathrm{mM}$ 2-morpholinoethanesulfonic acid $\mathrm{pH} 5.5,6.0]$ for $30 \mathrm{~s}$. Each point represents the mean $\pm \mathrm{SD}$ of four determinations. $* * p<0.01$ versus control

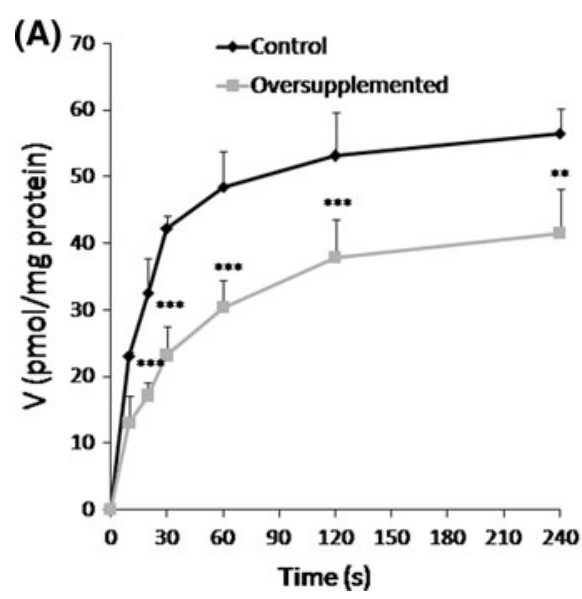

Fig. $3\left[{ }^{14} \mathrm{C}\right]-5$-methyltetrahydrofolate transport in renal BBMV at various a time and $\mathbf{b} \mathrm{pH}$ points. The incubation buffer $[100 \mathrm{mM}$ $\mathrm{NaCl}, 80 \mathrm{mM}$ mannitol, $10 \mathrm{mM}$ HEPES, $10 \mathrm{mM}$ 2-morpholinoethanesulfonic acid (MES)] containing $0.5 \mu \mathrm{M}\left[{ }^{14} \mathrm{C}\right]-5$ methyltetrahydrofolate was used for uptake measurements. a Transport was studied

Kinetic characterization of folic acid uptake across renal basolateral membrane vesicles

In case of BLMV, significant interaction was observed between time and oversupplemented dose only $(p<0.01)$. On studying the transport at various time intervals at $37{ }^{\circ} \mathrm{C}$ in control and folate-oversupplemented rats, an initial rapid increase in uptake was observed within $20-30 \mathrm{~s}$ in both groups. At different time intervals, the uptake was $5.1-23.6 \%$ less in the folate-oversupplemented rats $(p<0.01)$ (Fig. 6a). Upon studying the effect of $\mathrm{pH}$ on the folate transport across BLM, the $\mathrm{pH}$ of the incubation buffer was varied from 4.5 to 8 , keeping the intravesicular

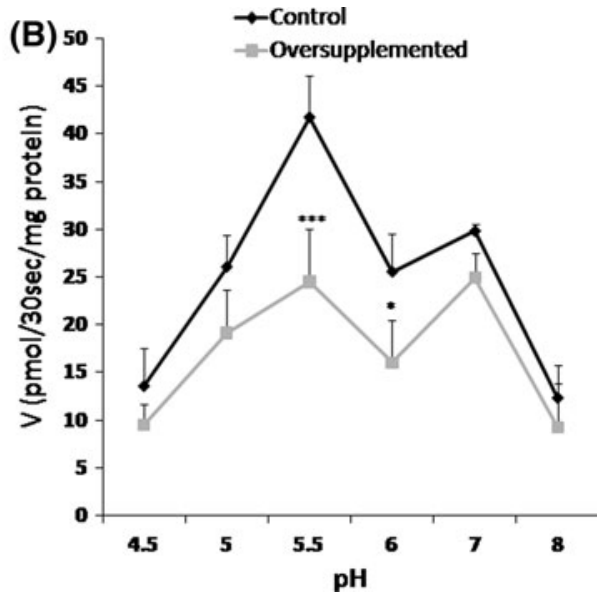

at different time intervals at a constant $\mathrm{pH}$ of 5.5. b Uptake was measured by varying incubation buffer $\mathrm{pH}$ from 5.0 to 8.0, keeping intravesicular $\mathrm{pH}$ 7.4. Each data point is mean $\pm \mathrm{SD}$ of 4 separate uptake determinations carried out in duplicate. $* p<0.05$; $* * p<0.01 ; * * * p<0.001$ versus control

$\mathrm{pH}$ constant at 7.4. Maximum folate uptake was observed at $\mathrm{pH} 6$ in both groups of rats (Fig. 6b). Folic acid uptake was $24.35 \%(p<0.05)$ less in the oversupplemented group at $\mathrm{pH} 6$. When the folate uptake was studied as a function of increasing concentrations of the substrate from 0.125 to $4.0 \mu \mathrm{M}$, the initial velocity determined at $30 \mathrm{~s}$ and at $\mathrm{pH} 6$ showed that, in both groups, the saturation phenomenon with a plateau at $1.0 \mu \mathrm{M}$ of the substrate concentration was indicative of the Michaelis-Menten kinetics (Fig. 7). In the concentration range of $0-1.0 \mu \mathrm{M}$, the uptake was $20.7-30.8 \%$ less in the folate-oversupplemented group $(p<0.01) . K_{\mathrm{m}}$ values determined from Lineweaver-Burk plot were not significantly different for the 


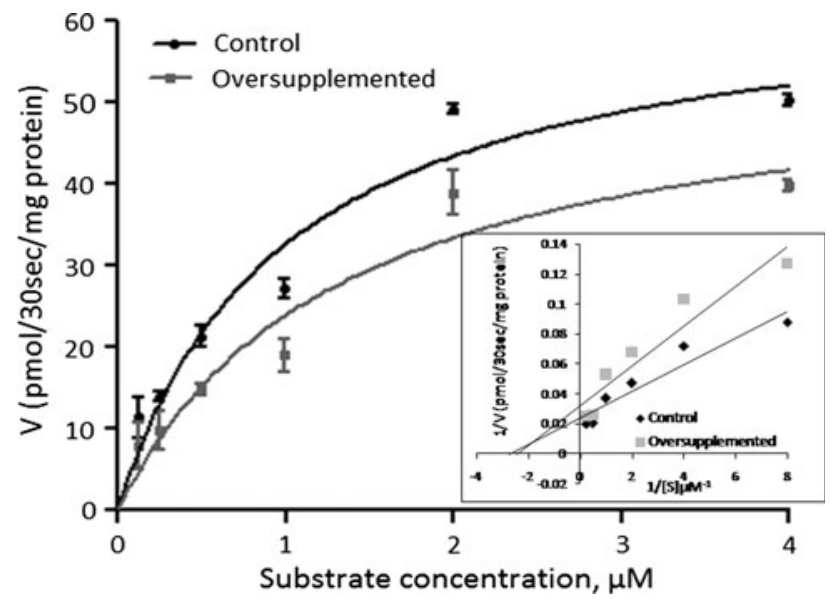

Fig. 4 Uptake of $\left[{ }^{14} \mathrm{C}\right]-5$-methyltetrahydrofolate in the renal BBMV as a function of substrate concentration. Uptake was measured by varying $\left[{ }^{14} \mathrm{C}\right]-5$-methyltetrahydrofolate concentration from 0.125 to $4.0 \mu \mathrm{M}$ in the incubation medium [100 $\mathrm{mM} \mathrm{NaCl}, 80 \mathrm{mM}$ mannitol, $10 \mathrm{mM}$ HEPES, $10 \mathrm{mM}$ 2-morpholinoethanesulfonic acid (MES), $\mathrm{pH}$ 5.5] after incubating BBMV for $30 \mathrm{~s}$. Each data point is mean \pm SD of 4 separate uptake determinations carried out in duplicate

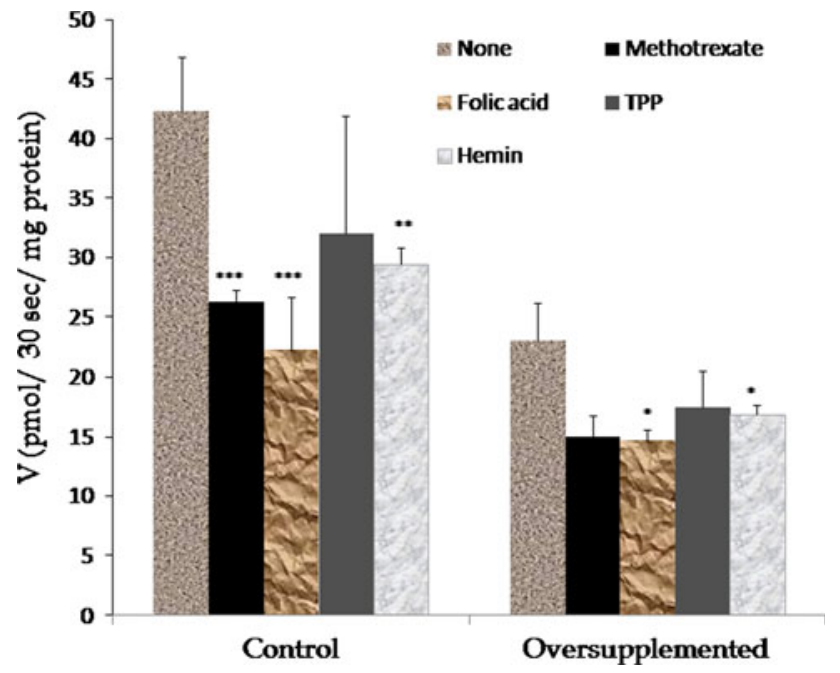

Fig. 5 Effect of structural analogs and inhibitors on the uptake of $\left[{ }^{14} \mathrm{C}\right]-5$-methyltetrahydrofolate in the renal BBMV. Uptake of $\left[{ }^{14} \mathrm{C}\right]-$ 5-methyltetrahydrofolate $(0.5 \mu \mathrm{M})$ was measured with and without analog/inhibitor in incubation buffer of $\mathrm{pH}$ 5.5. Each data point is mean $\pm \mathrm{SD}$ of four separate uptake determinations. $* p<0.05$; $* * p<0.01, * * * p<0.001$ versus none

control $(1.25 \pm 0.19 \mu \mathrm{M})$ and folate-oversupplemented $(1.27 \pm 0.32 \mu \mathrm{M})$ groups; however, the values of $V_{\max }$ for the control and folate-oversupplemented rats were $65.01 \pm 1.21$ and $55.5 \pm 2.12 \mathrm{pmol} / 30 \mathrm{~s}$ per $\mathrm{mg}$ protein, respectively $(p<0.01)$. Furthermore, folate transport was measured in the presence of the structural analogs and inhibitors. The structural analog methotrexate decreased the transport by $58.8 \%(p<0.001)$ and $62.8 \%$ $(p<0.001)$, and unlabeled folic acid decreased the transport by $15.68 \%(p<0.05)$ in the control rats; however, the change was not significant in oversupplemented rats, respectively. The inhibitor TPP decreased the transport by $31.4 \%(p<0.001)$ in the control and $34.2 \%$ $(p<0.001)$ in oversupplemented rats. However, there was no significant decrease in the transport of folate in the presence of hemin in both the groups (Fig. 8). Similar to BBM, there was no significant difference in the degree of inhibition of folate transport by these structural analogs and inhibitors in oversupplemented group as compared to control group.

Expression of mRNA corresponding to $r R F C$ and $r P C F T$

The findings that the folic acid uptake process is markedly decreased in renal BBMV with an appreciable decrease in $V_{\max }$, i.e., the number of transporters in the folate-oversupplemented group compared with the control group, led us to determine the mRNA expression of folate transporters. For this purpose, real-time RT-PCR analysis was performed using gene-specific primers for $r R F C, r P C F T$, $r F B P$, and $r G A P D H$ (as an internal control). Results showed that there was 1.92 -fold $(p<0.05)$ and 2.77 -fold $(p<0.05)$ decrease in the expression of mRNA coding for $r R F C$ and $r P C F T$, respectively, in acute folate-oversupplemented groups compared with the control group; however, there was no significant change in the mRNA expression in chronic oversupplemented group (Fig. 9a, b). There was no change in the expression of $r F B P$ in both the groups.

Expression of reduced folate carrier and proton-coupled folate transporter in kidney

Since there was significant change in the mRNA expression of folate transporters, the study was further extended to determine the regulation of folate transporters at the protein level. Western blot analysis was performed using specific polyclonal anti-rRFC and anti-rPCFT antibodies. Parallel to the results obtained on mRNA expression, there was a significant decrease in rRFC $(p<0.05)$ and rPCFT $(p<0.05)$ protein levels in folate-oversupplemented rats compared with the control rats, during acute folate oversupplementation. The decreased expression in the folateoversupplemented group was to the extent of $19.7 \%$ in rRFC and $26.4 \%$ in rPCFT in kidney. Parallel to the mRNA expression findings, there was no significant change in the protein expression of rRFC and rPCFT in the chronic folate-oversupplemented group compared with the control group. rFPB protein expression remained unchanged in both groups (Fig. 10a-c). 


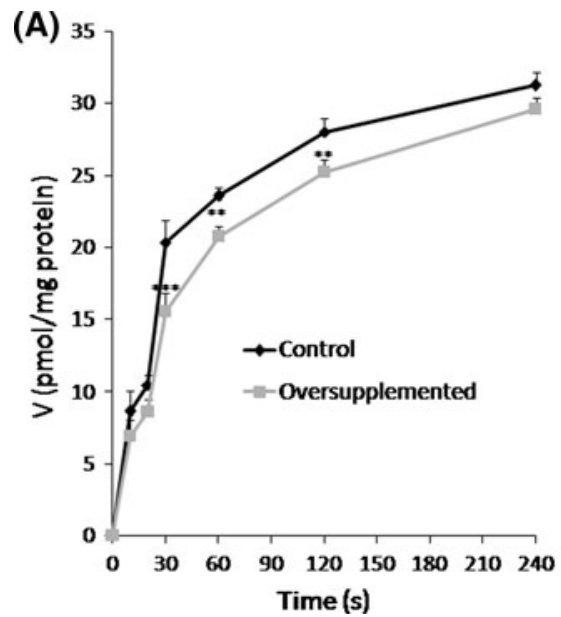

Fig. $6\left[{ }^{14} \mathrm{C}\right]-5$-methyltetrahydrofolate transport in renal BLMV at various time and $\mathrm{pH}$ points. The incubation buffer $[100 \mathrm{mM} \mathrm{NaCl}$, $80 \mathrm{mM}$ mannitol, $10 \mathrm{mM}$ HEPES, $10 \mathrm{mM}$ 2-morpholinoethanesulfonic acid (MES)] containing $0.5 \mu \mathrm{M}\left[{ }^{14} \mathrm{C}\right]-5$ methyltetrahydrofolate was used for uptake measurements. a Transport was studied at

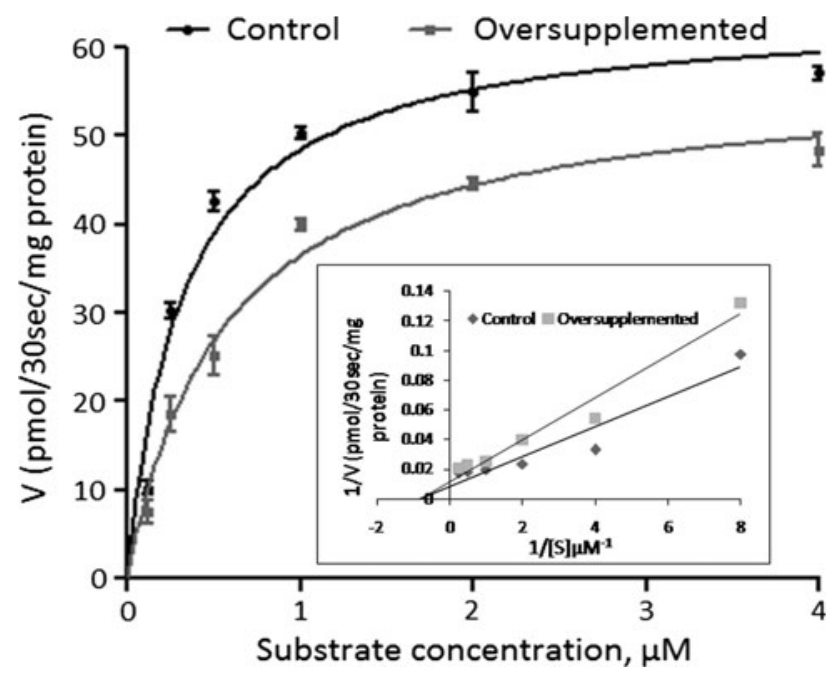

Fig. 7 Uptake of $\left[{ }^{14} \mathrm{C}\right]-5$-methyltetrahydrofolate in the renal BLMV as a function of substrate concentration. Uptake was measured by varying $\left[{ }^{14} \mathrm{C}\right]-5$-methyltetrahydrofolate concentration from 0.125 to $4.0 \mu \mathrm{M}$ in the incubation medium $[100 \mathrm{mM} \mathrm{NaCl}, 80 \mathrm{mM}$ mannitol, 10 mM HEPES, $10 \mathrm{mM}$ 2-morpholinoethanesulfonic acid (MES), $\mathrm{pH}$ 6] after incubating BBMV for $30 \mathrm{~s}$. Each data point is mean $\pm \mathrm{SD}$ of 4 separate uptake determinations carried out in duplicate

\section{Discussion}

High intake of folic acid bypasses the normal folate absorption mechanism, resulting in its increase in the serum (Kelly et al. 1997). The presence of unmetabolized folic acid in the circulation not only creates problem in the effective diagnosis of cobalamin deficiency of pernicious anemia but might be potentially harmful to the system. A high maternal folate intake exposes not only the pregnant woman to elevated levels of folate, but also the developing

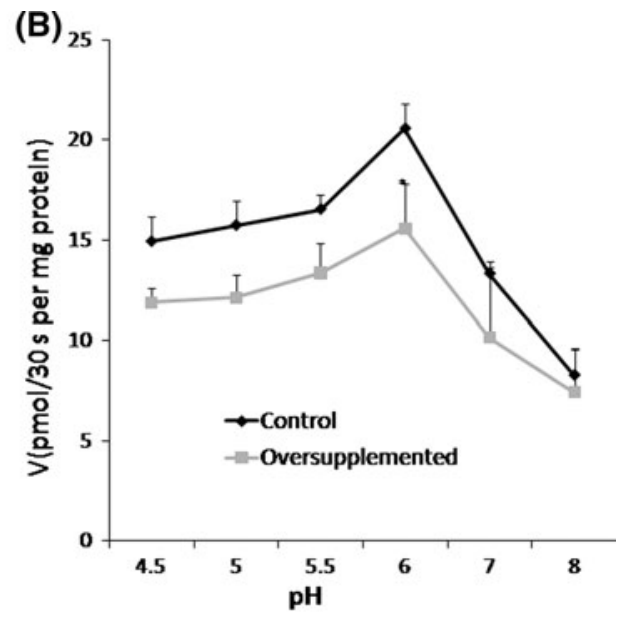

different time intervals at a constant $\mathrm{pH}$, i.e., 6. b Uptake was measured by varying incubation buffer $\mathrm{pH}$ from 5.0 to 8.0, keeping intravesicular $\mathrm{pH}$ 7.4. Each data point is mean $\pm \mathrm{SD}$ of 4 separate uptake determinations carried out in duplicate. $* p<0.05$; $* * p<0.011 * * * p<0.001$ versus control

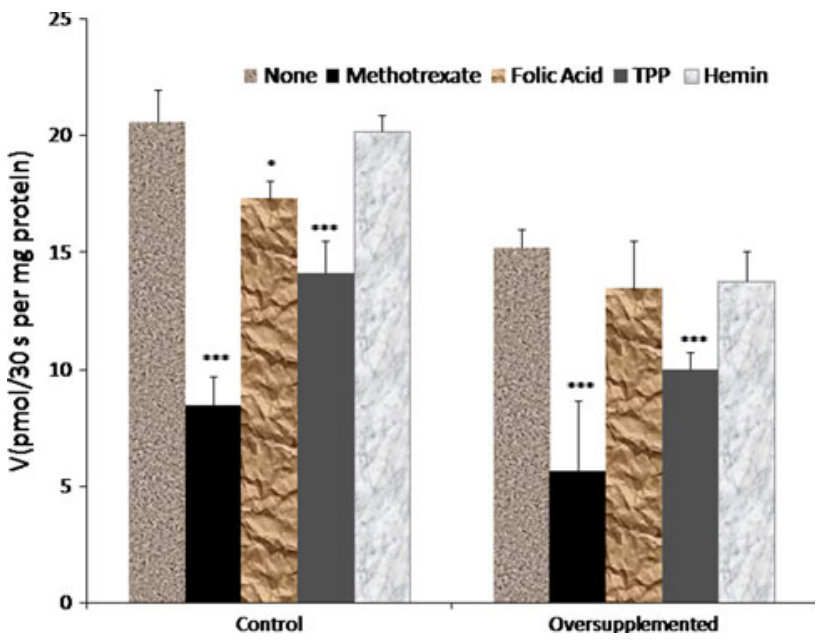

Fig. 8 Effect of structural analogs and inhibitors on the uptake of $\left[{ }^{14} \mathrm{C}\right]-5$-methyltetrahydrofolate in the renal BLMV. Uptake of $\left[{ }^{14} \mathrm{C}\right]-$ 5-methyltetrahydrofolate $(0.5 \mu \mathrm{M})$ was measured with and without analog/inhibitor in incubation buffer of $\mathrm{pH}$ 6. Each data point is mean $\pm \mathrm{SD}$ of four separate uptake determinations. $* p<0.05$; $* * p<0.001$ versus none

offspring. Several recent studies suggest that increased exposure to folate early in life may increase the risk of adverse health outcomes in the offspring, including obesity, insulin resistance, and asthma (Yajnik et al. 2008; Smith et al. 2008; Whitrow et al. 2009; Haberg et al. 2009). In our study, levels of glucose, triglycerides, and cholesterol in rat serum were not significantly different upon folate oversupplementation. The above-mentioned studies were conducted on humans, and adverse effects of folate and vitamin B12 oversupplementation were observed in the offsprings, which could be the reason for the observed 
Fig. 9 Real-time quantitative RT-PCR analysis of $R F C$, $P C F T$ and $F B P$ in a acute and b chronic oversupplemented rat kidney. Data shown are representative of 4 separate sets of experiments. ${ }^{*} p<0.05$ versus control
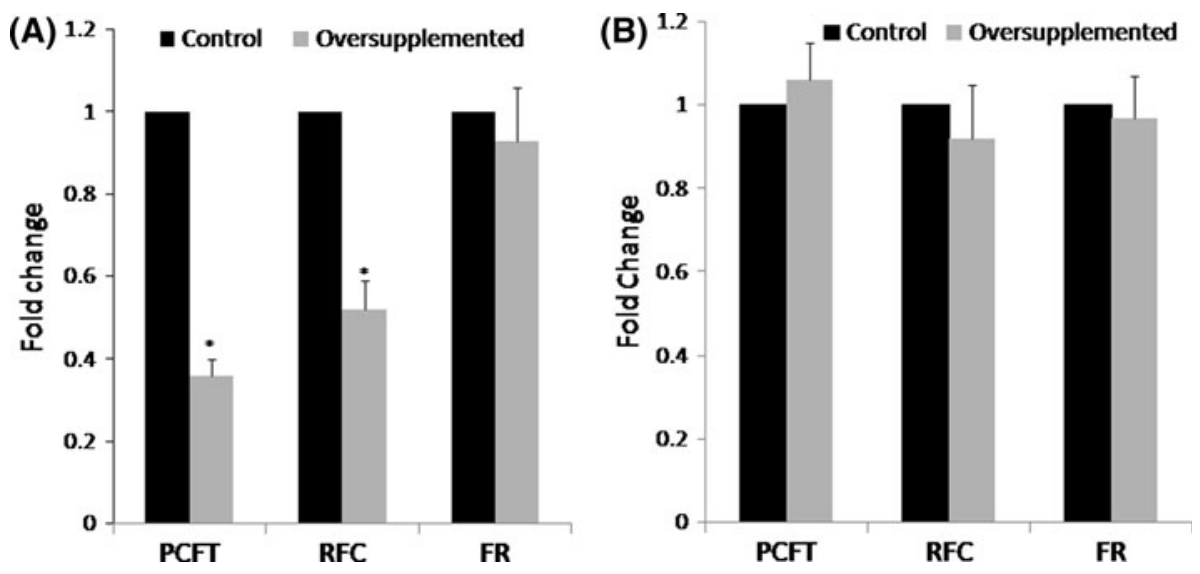

(A)

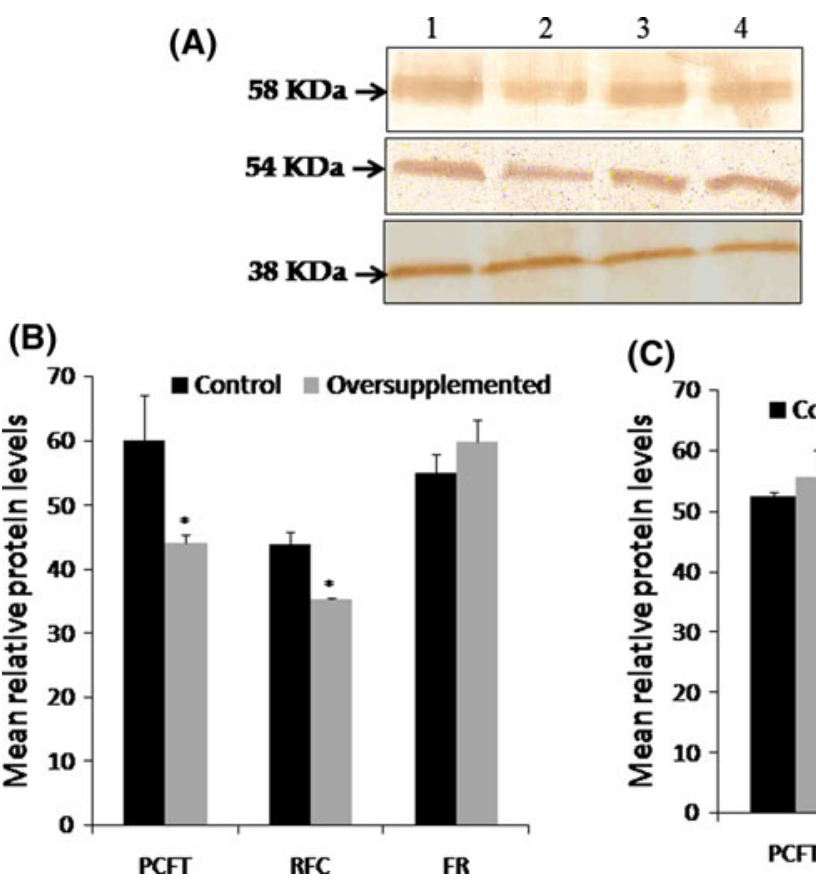

(B)

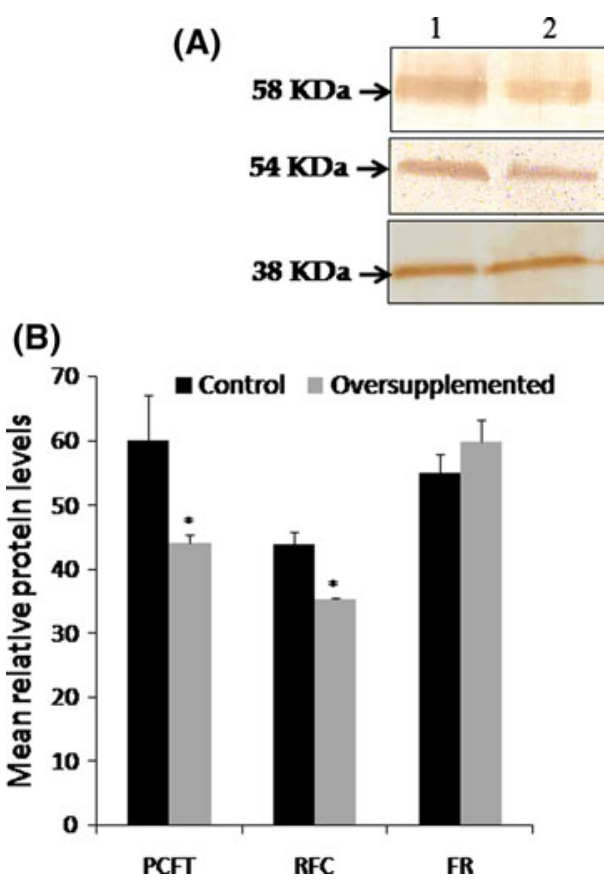

(C)

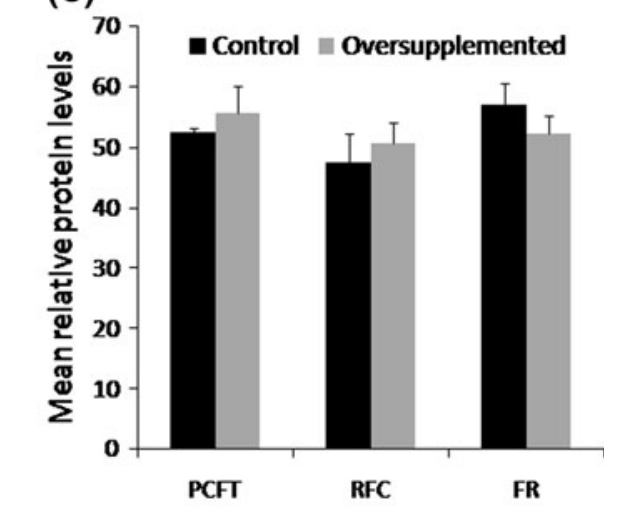

Fig. 10 Western blots analysis
of rat kidney lysate a using anti RFC (58 kDa), anti PCFT (54 kDa) and anti FBP (38 kDa) antibodies $\mathbf{b}$ densitometric analysis representing a relative change in rRFC, rPCFT and rFBP protein levels in acute oversupplemented rats representing a relative change in rRFC, rPCFT and rFBP protein levels in chronic oversupplemented rats. Graph represents summary data of densitometric analysis. Data are expressed are mean \pm SD of 4 separate experiments. a Lanes 1 and 3 control; lane 2 acute oversupplemented and lane 4 chronic oversupplemented. $* p<0.05$ versus control

contradiction in the results. Therefore, more controlled studies need to be conducted to conclude anything about the adverse effects of folate oversupplementation.

The present study has been done to investigate the effect of acute and chronic folic acid supplementation on renal transport system. Folate oversupplementation in rats was done by feeding ten times of normal folic acid, i.e., 20 $\mathrm{mg} / \mathrm{kg}$ diet for 10 days (acute group) and 60 days (chronic group). Because of the mandatory fortification of food with folic acid along with the high consumption of vitamin supplements in certain countries, people are being exposed to a very high amount of folic acid. Taking this into consideration, oversupplemented dose of folic acid was decided. Acute and chronic treatment duration was selected as per the previous reports (de Oliveira et al. 2008; Manso et al. 1995; Montesano et al. 1980; Reul et al. 1993; Dev et al. 2011). Rats fed on folate-oversupplemented diet did not show any significant change in their body weights as compared to control rats. The treatment was successful in inducing the folate-oversupplemented state as it results in 2.2-fold increase in serum folate levels of folate-oversupplemented rats compared with the controls (Dev et al. 2011).

Renal membrane vesicles isolated from control and oversupplemented group showed uptake in acidic microenvironment across both brush-border and basolateral membrane surfaces, suggesting that acidic microclimate is necessary factor for operation of the active component of the folate transport system across renal BBM and BLM. Both BBMV and BLMV followed saturable kinetics; however, as compared to control, there was a significant decrease in transport in the acute oversupplemented group. The down-regulation in the renal brush-border membrane folate uptake was found to be associated with decrease in 
number of transporter molecules (lower $V_{\max }$ ) along with altered affinity (higher $K_{\mathrm{m}}$ ) of transporter molecules toward their substrate. However, in case of renal BLMV there was no change in the $K_{\mathrm{m}}$, but $V_{\max }$ was found to be decreased, suggesting decrease in folate transporters on the cell membrane. The decrease in the number of transporters might reflect inhibition of some transcriptional, translational, or posttranslational event or increased degradation of these transporters during oversupplementation, and decrease in the affinity of the transporters might be because of some posttranslational modification or some other reason, which needs to be explored. Therefore, reduced uptake of folate through renal BBM and BLM during oversupplementation results in decreased reabsorption and might contribute to enhanced excretion in urine. $K_{\mathrm{m}}$ value across BBM was slightly higher as compared to BLM, suggesting that the transport across BBM is more efficient as compared to BLM.

To assess the specificity of the folate transport system, structural analogs and inhibitors were used. Different structural analogs such as folic acid and methotrexate decreased the folate uptake in BBMV and BLMV, hence validating the specificity of the transport systems. Unlabeled folic acid and methotrexate used in incubation medium reduced the uptake in both the groups, at both the membrane surfaces with same degree of inhibition in both the control and oversupplemented groups. Folic acid and methotrexate decreased folate transport more across BBM and BLM, respectively. Since PCFT has higher affinity for folic acid, as compared to methotrexate and RFC has higher affinity for methotrexate as compared to folic acid, this suggests that PCFT majorly expressed at BBM and RFC at BLM. This was further indicated using inhibitors of transport system, i.e., TPP (inhibitor of RFC) and hemin (weak inhibitor of PCFT). TPP and hemin significantly decreased the transport across BLM and BBM, respectively, suggesting major involvement of PCFT across BBM and RFC across BLM. Since there was no significant difference in the degree of inhibition of folate transport by these structural analogs and inhibitors in oversupplemented group, as compared to control group, this suggests that oversupplementation does not perturb the folate transporters structure and function. Across renal BBM, FBP is a major folate transporter involved in high affinity folate binding and transport.

In case of chronic folate oversupplementation, there was no change in the folate uptake at different time and $\mathrm{pH}$ points as compared to control. Similarly, on studying the effect of different structural analogs and inhibitors on folate uptake, similar inhibition was observed in both control and chronic oversupplemented group. Also, the $K_{\mathrm{m}}$ and $V_{\max }$ in chronic oversupplemented group was no different than control group, suggesting that on chronic folate oversupplementation of rats, the transport of folate resumes back to the control ones either due to some adaptive mechanisms or due to other reasons that are unknown (data not shown).

To evaluate the molecular mechanisms of down-regulation of folate uptake during acute oversupplementation, the expression study of folate transporters such as PCFT, RFC, and FBP was of prime importance, as these transporters are responsible for folate uptake across renal BBM and BLM. We found that there was a significant decrease in $r R F C$ and rPCFT mRNA levels in acute folate-oversupplemented rats as compared to control, whereas no change in the mRNA expression in chronic oversupplemented group. The down-regulation of renal folate uptake during acute folate oversupplementation was found to be associated with a parallel decrease in the protein levels of both RFC and PCFT transporters, suggesting the possible involvement of transcriptional and translational regulatory mechanism in regulating renal folate uptake under these conditions. Similar to the mRNA results, there was no change in the protein expression of rRFC and rPCFT in chronic folate oversupplementation. In case of FBP, there was no change in the expression in both the groups. To understand why under chronic folate oversupplementation there was no change in folate transport, more studies need to be conducted, which can elucidate the underlying mechanisms of adaptability.

Our results are in agreement with our previous study conducted on the effect of folate oversupplementation on intestinal folate transport in rats. However, in case of intestine, the reduced folate transport was associated with posttranscriptional and translational regulatory mechanisms for RFC and PCFT (Dev et al. 2011). Similarly, Ashokkumar et al. (2007) have shown that the folic acid transport by Caco-2 and HK-2 cells was significantly lower when cells were cultured in folate-oversupplemented condition for five generations. This reduction in folic acid uptake was observed to be associated with decrease in the mRNA and protein levels of the hRFC and decrease in mRNA levels of PCFT.

Down-regulation of folate transporters upon oversupplementation with folic acid may or may not have physiological relevance. When persons consuming high doses of folate experience serious acute illnesses such as catastrophic accidents, stroke, acute gastrointestinal disorders that lead to abrupt cessation of food intake, down-regulated renal tubular folate reabsorption in such circumstances can lead to significant depletion of this important essential nutrient at a time when its adequate supplies are critical to meet the heightened metabolic demands and reparative processes (Ashokkumar et al. 2007). Since in the current study down-regulation of folate transporters was observed in acute oversupplementation only and not during chronic 
oversupplementation, folate oversupplementation might not be producing any adverse effects in such cases. However, Ashokkumar et al. in their study on human intestinal and kidney cell line showed significant down-regulation of folate transporters on folate oversupplementation for five generations. Therefore, more studies need to be conducted to understand the consequences of folate oversupplementation. It would be interesting to see the effect of different doses and time duration of folate oversupplementation because worldwide, people are being exposed to different doses of folate and the time period of consumption of high amount of folic acid also varies, i.e., folate oversupplementation is more during pregnancy.

In the present study, folic acid supplementation increased the kidney folate levels, which might have contributed to an adaptive response resulting in decreased folate transporters expression and therefore reduced folate transport across the renal membrane surfaces. Further studies are, however, needed to have molecular mechanistic understanding, which could address the transcriptional regulation of folate transporters during folate oversupplementation.

Acknowledgments There is no funding agency supporting this work. All authors have contributed substantially to the paper and have read and approved the final manuscript.

Conflict of interest All authors declare that there is no potential conflict of interests.

\section{References}

Achon M, Reyes L, Alonso-Aperte E, Ubeda N, Varela-Moreiras G (1999) High dietary folate supplementation affects gestational development and dietary protein utilization in rats. J Nutr 129(6):1204-1208

Ashokkumar B, Mohammed ZM, Vaziri ND, Said HM (2007) Effect of folate oversupplementation on folate uptake by human intestinal and renal epithelial cells. Am J Clin Nutr 86(1):159-166

Bhandari SD, Joshi SK, McMartin KE (1988) Folate binding and transport by rat kidney brush-border membrane vesicles. Biochim Biophys Acta 937(2):211-218

Bhandari SD, Fortney T, McMartin KE (1991) Analysis of the pH dependence of folate binding and transport by rat kidney brushborder membrane vesicles. Proc Soc Exp Biol Med 196(4):451-456

Birn H, Spiegelstein O, Christensen EI, Finnell RH (2005) Renal tubular reabsorption of folate mediated by folate binding protein 1. J Am Soc Nephrol 16(3):608-615. doi:10.1681/ASN. 2004080711

Butterworth CE Jr, Tamura T (1989) Folic acid safety and toxicity: a brief review. Am J Clin Nutr 50(2):353-358

de Oliveira MR, Silvestrin RB, Mello e Souza T, Moreira JC (2008) Therapeutic vitamin A doses increase the levels of markers of oxidative insult in substantia nigra and decrease locomotory and exploratory activity in rats after acute and chronic supplementation. Neurochem Res 33(3):378-383. doi:10.1007/ s11064-007-9438-2

Dev S, Ahmad Wani N, Kaur J (2011) Regulatory mechanisms of intestinal folate uptake in a rat model of folate oversupplementation. Br J Nutr 105(6):827-835. doi:10.1017/S0007114510004538

Gregory JF 3rd, Quinlivan EP (2002) In vivo kinetics of folate metabolism. Annu Rev Nutr 22:199-220. doi:10.1146/annurev. nutr.22.120701.083554120701.083554

Haberg SE, London SJ, Stigum H, Nafstad P, Nystad W (2009) Folic acid supplements in pregnancy and early childhood respiratory health. Arch Dis Child 94(3):180-184. doi:10.1136/adc.2008. 142448

Hamid A, Kaur J (2006) Chronic alcoholism alters the transport characteristics of folate in rat renal brush-border membrane. Alcohol 38(1):59-66. doi:10.1016/j.alcohol.2006.01.004

Hamid A, Kiran M, Rana S, Kaur J (2009) Low folate transport across intestinal basolateral surface is associated with down-regulation of reduced folate carrier in in vivo model of folate malabsorption. IUBMB Life 61(3):236-243. doi:10.1002/iub.153

Jing M, Tactacan GB, Rodriguez-Lecompte JC, Kroeker A, House JD (2009) Molecular cloning and tissue distribution of reduced folate carrier and effect of dietary folate supplementation on the expression of reduced folate carrier in laying hens. Poult Sci 88(9):1939-1947. doi:10.3382/ps.2009-00032

Kelly P, McPartlin J, Goggins M, Weir DG, Scott JM (1997) Unmetabolized folic acid in serum: acute studies in subjects consuming fortified food and supplements. Am J Clin Nutr 65(6):1790-1795

Manso MA, Rebollo A, Pescador R, de Dios I (1995) Action of CCK on $\mathrm{CDE}$ diet-induced acute pancreatitis in rats treated with hydrocortisone. Comp Biochem Physiol C: Pharmacol Toxicol Endocrinol 111(2):257-263

Martel F, Goncalves P, Azevedo I (2006) Absorption of folate by Caco- 2 cells is not affected by high glucose concentration. Eur J Pharmacol 551(1-3):19-26. doi:10.1016/j.ejphar.2006.09.004

Montesano R, Bresil H, Planche-Martel G, Margison GP, Pegg AE (1980) Effect of chronic treatment of rats with dimethylnitrosamine on the removal of O6-methylguanine from DNA. Cancer Res 40(2):452-458

Qiu A, Jansen M, Sakaris A, Min SH, Chattopadhyay S, Tsai E, Sandoval C, Zhao R, Akabas MH, Goldman ID (2006) Identification of an intestinal folate transporter and the molecular basis for hereditary folate malabsorption. Cell 127(5):917-928. doi:10.1016/j.cell.2006.09.041

Qiu A, Min SH, Jansen M, Malhotra U, Tsai E, Cabelof DC, Matherly LH, Zhao R, Akabas MH, Goldman ID (2007) Rodent intestinal folate transporters (SLC46A1): secondary structure, functional properties, and response to dietary folate restriction. Am J Physiol Cell Physiol 293(5):C1669-C1678. doi:10.1152/ajpcell. 00202.2007

Reul JM, Stec I, Soder M, Holsboer F (1993) Chronic treatment of rats with the antidepressant amitriptyline attenuates the activity of the hypothalamic-pituitary-adrenocortical system. Endocrinology 133(1):312-320

Roncales M, Achon M, Manzarbeitia F, Maestro de las Casas C, Ramirez C, Varela-Moreiras G, Perez-Miguelsanz J (2004) Folic acid supplementation for 4 weeks affects liver morphology in aged rats. J Nutr 134 (5):1130-1133

Said HM, Chatterjee N, Haq RU, Subramanian VS, Ortiz A, Matherly LH, Sirotnak FM, Halsted C, Rubin SA (2000) Adaptive regulation of intestinal folate uptake: effect of dietary folate deficiency. Am J Physiol Cell Physiol 279(6):C1889-C1895

Scalera V, Storelli C, Storelli-Joss C, Haase W, Murer H (1980) A simple and fast method for the isolation of basolateral plasma membranes from rat small-intestinal epithelial cells. Biochem $\mathbf{J}$ 186(1):177-181 
Smith AD, Kim YI, Refsum H (2008) Is folic acid good for everyone? Am J Clin Nutr 87(3):517-533

Towbin H, Staehelin T, Gordon J (1992) Electrophoretic transfer of proteins from polyacrylamide gels to nitrocellulose sheets: procedure and some applications. 1979. Biotechnology 24:145-149

Troen AM, Mitchell B, Sorensen B, Wener MH, Johnston A, Wood B, Selhub J, McTiernan A, Yasui Y, Oral E, Potter JD, Ulrich CM (2006) Unmetabolized folic acid in plasma is associated with reduced natural killer cell cytotoxicity among postmenopausal women. J Nutr 136(1):189-194

Ulrich CM, Potter JD (2006) Folate supplementation: too much of a good thing? Cancer Epidemiol Biomarkers Prev 15(2):189-193. doi:10.1158/1055-9965.EPI-152CO

Villanueva J, Ling EH, Chandler CJ, Halsted CH (1998) Membrane and tissue distribution of folate binding protein in pig. Am J Physiol 275(5 Pt 2):R1503-R1510

Wang Y, Zhao R, Russell RG, Goldman ID (2001) Localization of the murine reduced folate carrier as assessed by immunohistochemical analysis. Biochim Biophys Acta 1513(1):49-54. doi:10.1016/ S0005-2736(01)00340-6

Wani NA, Nada R, Kaur J (2011) Biochemical and molecular mechanisms of folate transport in rat pancreas; interference with ethanol ingestion. PLoS ONE 6(12):e28599. doi:10.1371/ journal.pone.0028599PONE-D-11-06356

Whitrow MJ, Moore VM, Rumbold AR, Davies MJ (2009) Effect of supplemental folic acid in pregnancy on childhood asthma: a prospective birth cohort study. Am J Epidemiol 170(12):1486-1493. doi:10.1093/aje/kwp315

Williams WM, Huang KC (1982) Renal tubular transport of folic acid and methotrexate in the monkey. Am J Physiol 242(5):F484F490

Yajnik CS, Deshpande SS, Jackson AA, Refsum H, Rao S, Fisher DJ, Bhat DS, Naik SS, Coyaji KJ, Joglekar CV, Joshi N, Lubree HG, Deshpande VU, Rege SS, Fall CH (2008) Vitamin B12 and folate concentrations during pregnancy and insulin resistance in the offspring: the Pune maternal nutrition study. Diabetologia 51(1):29-38. doi:10.1007/s00125-007-0793-y 